\title{
Smart Cities and $M^{3}$ : Rapid Research, Meaningful Metrics and Co-Design
}

\author{
Simon Bell ${ }^{1}$ (D) $\cdot$ Francesca Benatti $^{2} \cdot$ Neil R. Edwards ${ }^{1}$ • \\ Robin Laney ${ }^{1}$ - David R. Morse ${ }^{1}$ - Lara Piccolo ${ }^{3}$. \\ Oliver Zanetti ${ }^{2}$
}

Published online: 20 May 2017

(C) The Author(s) 2017. This article is an open access publication

\begin{abstract}
The research described in this paper is undertaken under the banner of the smart city, a concept that captures the way urban spaces are re-made by the incursion of new technology. Much of smart is centred on converting everyday activities into data, and using this data to generate knowledge mediated by technology. Ordinary citizens, those that may have their lives impacted by the technology, usually are not properly involved in the 'smartification' process. Their perceptions, concerns and expectations should inform the conception and development of smart technologies at the same extent. How to engage general public with smart cities research is the central challenge for the Making Metrics Meaningful (MMM) project. Applying a rapid participatory method, 'Imagine' over a five-month period (March - July) the research sought to gain insights from the general public into novel forms of information system innovation. This brief paper describes the nature of the accelerated research undertaken and explores some of the themes which emerged in the analysis. Generic themes, beyond the remit of an explicit transport focus, are developed and pointers towards further research directions are discussed. Participatory methods, including engaging with selfselected transport users actively through both picture creation and programmatically specific musical 'signatures' as well as group discussion, were found to be effective in eliciting users' own concerns, needs and ideas for novel information systems.
\end{abstract}

Keywords Smart cities $\cdot$ co-design $\cdot$ rich pictures $\cdot$ systemic method

Simon Bell

simon.bell@open.ac.uk

1 Faculty of Science Technology Engineering and Mathematics (STEM), Open University, Milton Keynes MK7 6AA, UK

2 (FASS), Open University, Milton Keynes MK7 6AA, UK

3 (KMI), Open University, Milton Keynes MK7 6AA, UK 


\section{Background to and Overview of the Research Context}

The research described in this paper was undertaken by a team which was thrown together at a 'Sandpit' event at the Open University on the 8th February 2016. The team members were from different Faculties and many of them had not met before the 8th. In four hours the team formed, came up with an idea for research, presented that idea to gate-keepers and were awarded funding. By the 20th July the research was finished.

Between the 8th February and the 20th July the team firmed up their initial research idea about how metrics and data more generally can be made more meaningful to the public - into a focused assessment of public engagement with public transport information provision in smart cities. The research has involved seven active academics and has engaged over 30 members of the public in two workshop events in Milton Keynes. The research has innovated a fresh interpretation of the visualisation diagram, the 'Rich Picture', and provided an opportunity for the public to translate their wishes related to a better transport in the city into ideas for an innovative technology co-designed by them.

In outline, in this paper we set the context for public transport in Milton Keynes, the nature of Smart Cities and the systemic issues which they evoke. Building on this the article explores the literature around transport and the implications of non-inclusion for citizens. In the context of the literature our research question emerges with clear focus on the citizens' requirement for transport knowledge. We then describe our research process, the methods engaged and the outcomes of the Action Research Workshops engaged. Finally, we conclude with some modest recommendations.

\section{Context - Public Transport in Milton Keynes}

The research is located in Milton Keynes (MK), in the United Kingdom. The intentions of the study were both to build upon existing knowledge of smart cities (see below), but also to reflect on matters of concern specific to the city. MK is a small but growing city with a population in 2016 of around 230,000. The city is located near London and expecting both population and economic growth in the future. The city faces two issues pertinent to its public transport system: its physical infrastructure and the place of public transport in the political life of the city.

MK is a new city, famously, and has a very particular form of infrastructure. It is a car centred city which operates through an $11 \times 10$ grid system of arterial roads on which traffic tends to run at motorway speeds. Those grid roads are placed at approximately $1 \mathrm{~km}$ intervals and the spaces between them hold residential areas. These are formed of estates, which are traversed through networks of low speed, often curved, residential streets, accessed from only one or two points on the grid roads. Long distance pedestrian and cycling provision is available through the "Redways" ", routes free of motorised traffic that broadly follow the grid roads. The city's road infrastructure creates unique challenges to public transport in MK. Unlike cities which follow the classic Victorian design, MK's main roads do not also operate as local centres. This makes the 'hubbing' effect that public transport typically relies upon less pronounced in MK. The distributed population combined with the longer distances which

\footnotetext{
${ }^{1}$ A cycle network in Milton Keynes - see: https://www.milton-keynes.gov.uk/streets-transport-andparking/cycling/cycle-routes-and-maps
} 
must be covered by buses to access residential areas via the grid roads present particular challenges.

Moreover, public transport use has tended, until recent years, to be regarded as a secondary priority to private car use, and public transport users have observed that the provision is often inefficient and unreliable. MK is known as a car dependent city (http://www.bettertransport. org.uk/media/10-december-2014-car-dependency\%20research), though the 2011 census reveals that nearly $19 \%$ of the city's households do not have access to a car $(18,656$ households of a total of 98,584 - see http://www.ons.gov.uk/ons/rel/census/2011-census/keystatistics-for-local-authorities-in-england-and-wales/rft-table-ks404ew.xls). Thus there is a need for a more focused and holistic approach to public transport to improve mobility.

\section{Context - Systems and Smart Cities - But where are the People?}

Transport systems often emerge with unintended consequences due to a lack of holistic forethought. In this journal Khirsty and Zeitler identified some of the challenges which mobility provide in a systemic context (Jotin Khisty and Zeitler 2001). Transport is clearly an issue/ concern which, by its inter-connectedness and multiple layers provides an opportunity for systemic problem structuring (Ülengin et al. 2010) and a participatory approach (Farkas et al. 2014; Carlsson-Kanyama et al. 2008).

One of the requirements for our research was to be systemically clear on terms and meanings in this confusing area. For example, there is a lot of academic work that goes on under the banner of 'smart cities'; which is ironic given that much of that work begins with a short discussion about the fluidity of the term smart city itself.

"The term 'smart city' has been variously defined within the literature..." (Kitchin 2014: 1).

This quote from Kitchin is one example of many. Broadly, attempting to avoid a lot of detail, this is because the terminology of smart city preceded many of the technologies today defined as 'smart'. Thus, as one version of 'smart' was created, the technology moved on and new technological practice was retrofitted into a pre-existing landscape of terminology. Likewise, smart has a huge range of proponents from sectors whose cultural, commercial and political priorities differ widely, each of whom lend their support to a version of smart which corresponds to their particular interests.

The research described in this paper is undertaken under the banner of smart city research too. For clarity, in this project we employ a definition of the smart city with a wide purview, understanding it as a piece of conceptual terminology which explores the way urban spaces are re-made by the incursion of new technology and/or the digital.

The production and usage of data is central to smart cities. Almost always quantitative, data are the tool by which the messiness of human / urban life can be made meaningful to a computer system. Much of smart is centred on converting everyday activities into data. And transport is one of those central places where this occurs.

\section{Literature Reviews of the Transport Data Landscape Reveal a Focus on Two Areas}

The first is the increasing use of smart ticketing technologies like the Oyster card in megacities such as London (for a wider debate see: Coskun et al. 2014). These technologies allow 
very detailed collection of data on transport users' activities as they move around the system (Nishiuchi et al. 2013). In other situations, where expensive technologies like smart ticketing are not available, citizens are enrolled to provide data on their movements. Often incentivised in some way, citizens activate an app on their phone which tracks their movements through the phone's location services and feeds back to the app's creator (which could be either the transport network itself, or it could be an independent body). These apps have been used to measure, for instance, the real time movement of trams or buses so that public transport users can receive live modifications to a printed timetable. Similarly, Google Maps' traffic app uses the real time movements of Google Maps app users to identify and label traffic blockages on the roads (for a compendious discussion of the area see Mac-Gillavry 2013).

Two things are of interest for the research described here.

- First, as is perhaps inevitable in the early use of a technology, the data landscape has focussed on what it is possible to collect rather than what is necessarily required by transport users. This means that there is a natural tendency for data to be moulded to a use rather than the use being identified first and data being collected to answer that use.

- Second, data tends to be funnelled upwards to public transport operators (such as Transport for London or app developers). These operators may choose to make data available, but they may not necessarily do so. This is not automatically a world of open data.

Tomitsch and Haeusler (2015) talk about infostructures as being complementary to infrastructures. By this, they mean that collection and deployment of good data can help to enhance use of urban infrastructure and do so more cheaply. In simple terms, a new train line is expensive to construct, while providing people with data that shows when the existing infrastructure is less busy and encourage people to plan their travel accordingly could be a substantially cheaper means to reduce the pressure on infrastructure and improve the quality of travellers' journeys.

That said, we also know that people do not simply make better decisions because there is more data available. The factor which is most influential in whether urban dwellers make use of an expanded data landscape that makes public transport use easier and more efficient is whether they are accustomed to using public transport already (Farag and Lyons 2010, 2012). Providing new data and better ways for people to navigate the system is useful, but, if there is a policy incentive to encourage people to use public transport, better technology is not what is going to achieve that. People will need to be encouraged onto the transport network first of all. This raises the question of what role citizens play in the underlying data structures. Participation can be inclusive and there are degrees of inclusivity. For example, in June 2016, the Milton Keynes "Hackathon" supported by the 'MK Smart' research project ran a weekend event where users and app developers got together voluntarily over a weekend to work on an app which will help people navigate the Redways' in Milton Keynes.

It can be argued that if research involves a detailed and comprehensive use of metrics then it will tend to be experienced as excluding of the general public - the metrics ensure that there will be a cognitive and cultural barrier to wider participation - largely due to the exclusivity of access to and familiarity with technical knowledge. We endeavoured to break down these barriers to exclusivity by adopting a co-design or participatory design research methodology. This is a mode of design practice in which the users are participants in design practice as well as the design experts (from business, academia, and so on). 
Participatory inclusion or 'co-design' in research processes is an established, multidisciplinary concept, having been practiced in a number of fields for a good few decades (see for example: Chambers 1995; Fraser et al. 2006; Buscher et al. 2002; Cinderby 2010), and it is also a design concept which is gaining traction as commerce becomes more rooted around experience than physical goods as products - Sanders and Strappers (2008) elaborated on the co-design process as shown in Fig. 1.

The process works by (following the chart along) bringing people in at the beginning of the product cycle (before the designers even know what they want to make, more or less), allowing people to have ideas that might pull the design process in a range of directions before, later on, using both them and the design team to hone those ideas. Not restricted to desirable technical features, the ideas discussed usually also reveal constraints related to current regulation, market organisation, among other formal constraints, and more social and informal aspects such as personal values, habits, local culture, and so on.

This sociotechnical and more holistic approach underlay our research method:

\section{Research Question, Approach and Focus}

Given our concerns regarding the top-down and expert-driven nature of existing metrics and our interest in involving the public in co-design, our initial research began with a simple question for public transport users in Milton Keynes:

"What information issues do you encounter when you consider the transport options you have to make on a daily basis?"

Following a couple of iterations, we refined this question in such a manner as to be easy to grasp and less off-putting in terms of subliminal assumptions (e.g. regarding existing knowledge/ expertise, etc.). The final form of our question was:

\section{"What do I Wish I'd Known before I set Out or during My Journey?"}

Early on the research team adopted a research approach and focus in order to explore this question. The approach and focus is set out in Fig. 2. At this stage a specific research application had not yet been defined, the reference to agent-based modelling in Fig. 2 indicates a potential link to detailed predictive modelling analysis with a person-centric, 'bottom-up' modelling paradigm matching that of the Imagine methodology used in the co-design process described here.

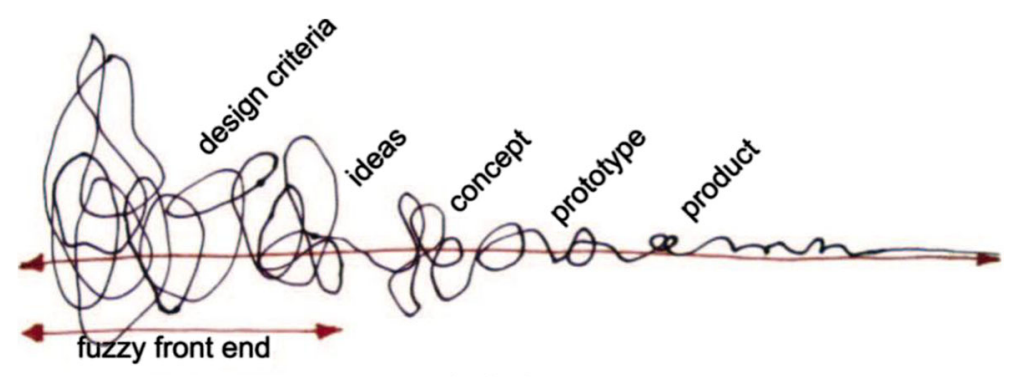

co-designing

Fig. 1 Co-design. (Source: Sanders and Stappers 2008, p. 6) 


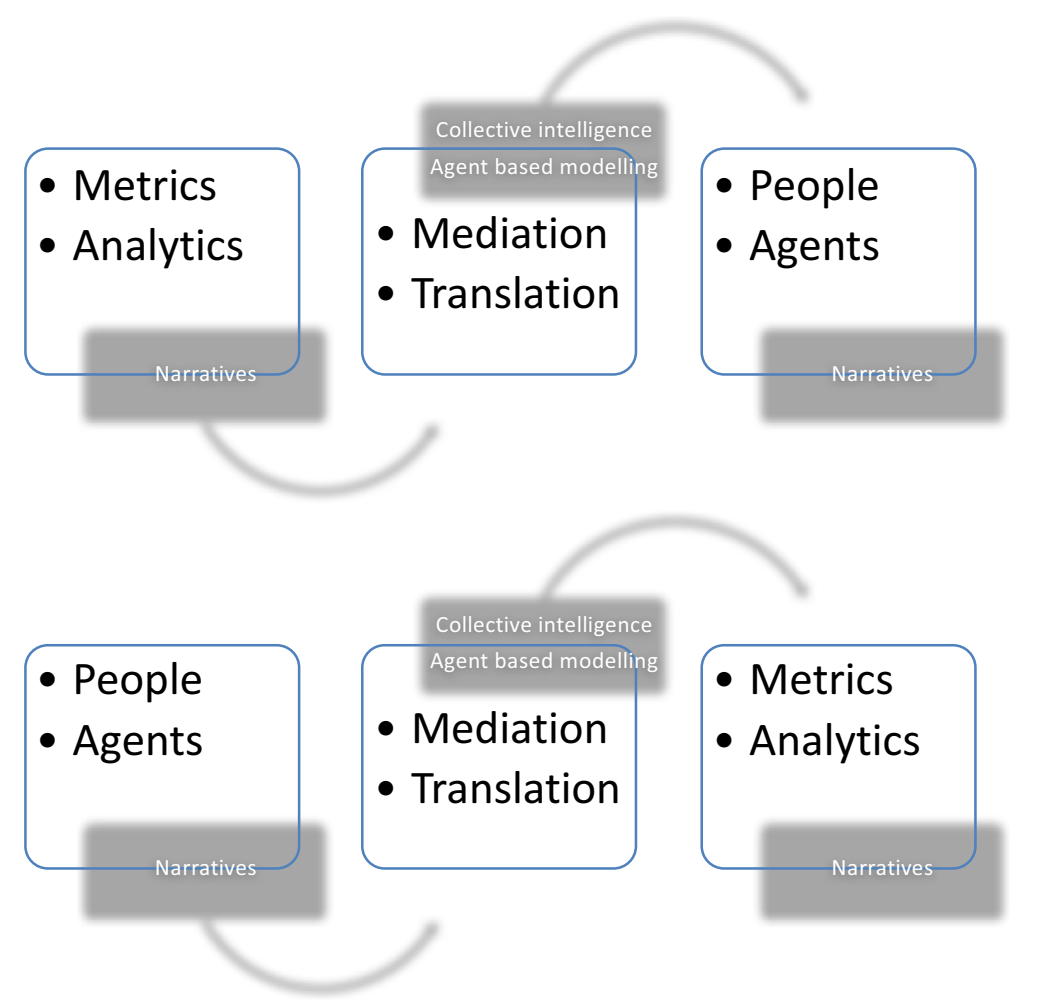

Fig. 2 Research approach and three key areas of focus

The approach combines three elements in two dynamic combinations:

- The first element is metrics and analytics for transport in smart cities

- Secondly the mediation and translation of these metrics and analytics - assumed to involve an 'app' of some kind.

- Thirdly, the users of the translated metrics.

In the second part of the Figure these three are shown in reverse order. Thus metrics informs application and this is provided to users/ publics. But, at the same time the public provides demands on the nature of the app and this in turn determines the data requirement.

For both metrics and users/people, the research team were interested in exploring narratives and stories which set out the main concerns and needs of the public for information on journeys involving public transport (on the one hand) and the limitations and uses of data (on the other).

As urban communities become smarter, data plays an increasingly significant role in their organisation and management. But neither as an object nor in the processes of its collection should data be considered value free or objective (Kitchin 2014). Instead, data can be understood as both partial and fallible. Knowing this, the aim of this exploratory project was to work with members of the public in MK to identify how they were served, or not, by the existing data landscape in relation to transport, and particularly public transport, in the city. In doing so, our aim was to provide members of the public with the opportunity to take a lead in 
considering their transport requirements and what improvements they would want to see applied to that data landscape. Following Tomitsch and Haeusler (2015), it is helpful to understand cities as being composed of physical infrastructures which it is now possible to enmesh with data led 'infostructures'. These infostructures make it possible to enhance the utilisation of existing physical infrastructure, a far cheaper and less resource intensive proposition than new material constructions. In a city like $\mathrm{MK}$, where infrastructure is not currently stretched but the population is projected to grow by $20 \%$ between 2012 and $2026,{ }^{2}$ now is an appropriate moment to be considering such questions. This brief review considers two key areas discussed in the literature.

- First, it looks at the workings of the existing transport data landscape;

- Secondly, it examines the way transport users are able to participate in bringing about the tools to utilise or manipulate this data.

\section{The Existing Data Landscape}

Data plays a critical role in urban transport planning and has received considerable attention in the literature. It is known that transport data is more likely to be available in urban areas, and that newer technologies, such as real time updates, are also more commonly employed in cities (Velaga et al. 2012). A key question for this project surrounds the way by which that data is collected, and for whom it is collected. A considerable amount of data is accumulated from new smart payment systems for urban transport networks, and there are various pieces of work which assess the functionality, utility, and ethical implications of the accumulation of that data (Allwinkle and Cruickshank 2011; Avoine et al. 2014; Bagchi and White 2005; Pelletier et al. 2011). Echoing broader moves in smart city activity towards crowdsourcing or citizen sensing (Gabrys 2014; Salim 2012), where smart ticketing systems are not available, the users of public transport have been enrolled to generate data using their own devices (Farkas et al. 2014, 2015; Thiagarajan et al. 2010). Interestingly, these existing studies of data accumulation tend to be centred on what kind of data it is possible to accumulate rather than what kinds of data would be useful for public transport users. Instead of seeking to find data to fit the problems, what our review appears to suggest is that data is generated and the learning it makes possible is retro-fitted to the problems. While technological development traditionally plays an important role in leading the creation of new, unimagined possibilities and markets, our review nevertheless implies that there is an important gap in the literature which is centred around user-driven demand for data. This is a gap which the current research has sought to address. The question for research (such as that contained in the $\mathrm{M}^{3}$ project) begins, not with what data it is technically possible to collect, but with an assessment of what users of transport systems require. Some examples of the utility of this approach exist. For instance, in Dhaka, crowdsourced data was employed to produce the first public transport map in a city in where, though many citizens would find a map useful, a lack of formal organisation of the public transport network had made such a map unrealisable (Zegras et al. 2015).

The question of how to produce data which directly responds to transport users' requirements is significant given what we know about how data influences the way travellers make

\footnotetext{
${ }^{2}$ See: http://www.milton-keynes.gov.uk/social-care-and-health/draft-2015-16-jsna/draft-2015-16-jsna-population-and-places/2015-16-draft-jsna-population-and-growth
} 
use of transport networks. It is known that people may not make personal transport choices that fit with their desires for the urban areas they inhabit - taking the car while simultaneously wishing for a less polluted city, for instance- and it is thought that the provision of better transport data might reduce such instances by facilitating increased public transport use (Lisson and Hall 2016). However, other research has found that while better data provision enhances the experience of public transport use amongst existing public transport users, the provision of data on its own does not encourage users on to public transport who are not already habituated with the networks (Farag and Lyons 2010, 2012). The ways in which public transport data used by travellers is also important. Public transport data is employed by the public to reduce travel time and affective effort or stress while en route, whereas information which will help reduce the cognitive or physical effort of travelling is collected before departure (Grotenhuis et al. 2007). Data may also be used by travellers to alter their route choices as they are travelling (Trozzi et al. 2015).

\section{Transport Users Ability to Participate in Bringing about the Tools to Utilise or Manipulate this Data}

Experimental work on how to deliver the data accumulated is present in the literature. In this review, we have briefly surveyed a series of articles which describe how apps are created, though these focus on the technical aspects of app development undertaken by professionals (Barbeau et al. 2014; Mirri et al. 2014; Nuzzolo et al. 2013). Also illustrative is work which has examined the best way to present QR $\operatorname{codes}^{3}$ on posters located in bus stops in order to direct travellers to a website which delivers information on forthcoming buses (Gammer et al. 2014). Citizen co-created applications (Desouza and Bhagwatwar 2012) exist in the world of transport use (Baraniuk 2013; Anon 2016; Paradi-Guilford et al. 2013), some of them designed with the purpose of persuading more sustainable transport choices (Mitchell et al. 2015). While this has opened up the arena from a purely top down approach, what is not addressed by this relative democratisation is the possibility of participation by those who do not have the time or technical skills to undertake app creation themselves. The $\mathrm{M}^{3}$ project has had this mode of engaging publics at its heart.

To conclude, then, this literature review has highlighted two key points within which the $\mathrm{M}^{3}$ study is located. The first is that transport data exists and is valuable, but that commonly the kinds of data which are collected are those which existing or new infrastructures make possible, rather than those specifically designed to be of relevance to travellers. We have come across no projects which have attempted to do what we have done; rather, approaches to data seem to be largely top down. Yet we know, from this research, that users have particular requirements from data which might not necessarily be best served by the kinds of data which are currently collected. Second, and building on the first point, this literature review has demonstrated that spaces for citizen participation are limited to those with the technical skills to undertake technical developments. While much data is made open, often via the General Transit Feed Specification also known as the.GTFS file type ${ }^{4}$ there is little scope for wider

\footnotetext{
${ }^{3}$ A QR code is "a type of two-dimensional machine-readable code consisting of an array of black and white squares, typically used for storing URLs or coding information for reading by a camera phone". "Q, n.". OED Online. June 2016. Oxford University Press. http://www.oed.com.libezproxy.open.ac.uk/view/Entry/155604 ?rskey=6iOceW\&result=1 (accessed September 01, 2016).

${ }^{4}$ GTFS is described here https://developers.google.com/transit/gtfs/
} 
public participation, and examples of lay publics being directly enrolled in decision making processes in the way addressed by this research were not found.

\section{$\mathrm{M}^{3}$ Project Process and Method}

At the outset, the $\mathrm{M}^{3}$ project team identified a series of stages to the project process. Broadly speaking these were as follows:

- Initial workshop with local users:

- identify and engage local users concerns regarding meaningful metrics for transport decision making in Milton Keynes.

- Assess the data requirements for the specified concerns/ issues

- Assess the technology / app issues for the specified concerns

- Preliminary analysis of user input, distillation of main themes, musical signature composition etc.

- Second workshop with local users:

- identify potential means to realise technologies which can assist with transport decisions in terms of user interface design, data and socio-technical requirements.

Key to the process was a means to engage the public in Milton Keynes and for this the Imagine method was selected. Imagine (Bell and Morse 2010) is a community engagement method broadly based upon the Soft Systems Method of Checkland, but deliberately ordinated around the Kolb learning cycle and previously applied widely in environmental contexts - specifically relating to the application of metrics to issues of local sustainability (Checkland and Poulter 2006; Kolb 1984; Bell et al. 2013). The Imagine method was developed as a means to engage local populations in co-design of sustainability measurement and in problem structuring (Pidd 2011; Bell and Morse 2013) by engaging this population in the consideration of what is important, what is the current state of important things, and how they can be measured. The objective of the method is to gain information on data and indicators from mixed lay/ technical communities. It was always intended that Imagine be a methodology in the fullest sense of the term, evolving with time and capable of being cut and edited to meet requirements of local context.

Notwithstanding this flexibility, the key element of the method is the Rich Picture or RP (for a fuller description see Bell et al. 2016):

"The RP has been around for many years and is a cartoon-like diagram which encourages people to apply what Rose Armson brilliantly described as 'optimal indiscretion' to explore complex issues and, in many cases, set out realities and truths which, for one reason or another, cannot easily be spoken about or written formally. RPs contain this 'release' function, providing indiscreet insight into troublesome areas. We argue that the RP drawing enriches problem-solving and, in the long term, saves time and resources from being expended on erroneous and/or superficial tasks. RPs embody the commonly expressed view that "pictures paint a thousand words'." (Bell et al. 2016, page x) 
The RP is a device for gaining spontaneous and unguarded thoughts (as well as considered and guarded ideas) from groups of around 5-10 stakeholders. A RP is shown in Fig. 3.

A RP is a free form diagram with few rules other than to use as few words as possible. It is produced by a group on a large poster sheet of paper with coloured marker pens. This sample $\mathrm{RP}$ is taken from a project relating to the sustainability of the coastal fringe that took place in Lebanon. It is one of four produced at the same time by different stakeholder groups. Such a picture (Fig. 3) can be assessed by a form of Content Analysis, as the description in Table 1, below, illustrates.

To explain the content analysis is a little more detail:

Column 1 contains the major themes drawn out by the research team assessing this and any other RPs produced at the same time in the same workshop. These themes are common to all RPs.

Column 2 contains the specific relationship between this RP and the themes in column 1. Column 3 contains the themes mentioned by Stakeholders when they described their RP in a summarising session following the drawing process. The colour coding relates to similar themes which emerged across the other RPs which emerged in the workshop.

The penultimate row contains the plenary reflections summarising the RP as provided by the Stakeholders.

The final row is the research team's overall assessment of all the previous information.

It contains the unique 'signature' of the RP which draws upon all the previous information. This is produced by the research team but can be developed in collaboration with the workshop participants.

This approach to Content Analysis is called Eductive Interpretation Content Analysis or EICA (for an overview of the approach see: Bell et al. 2015, 2016).

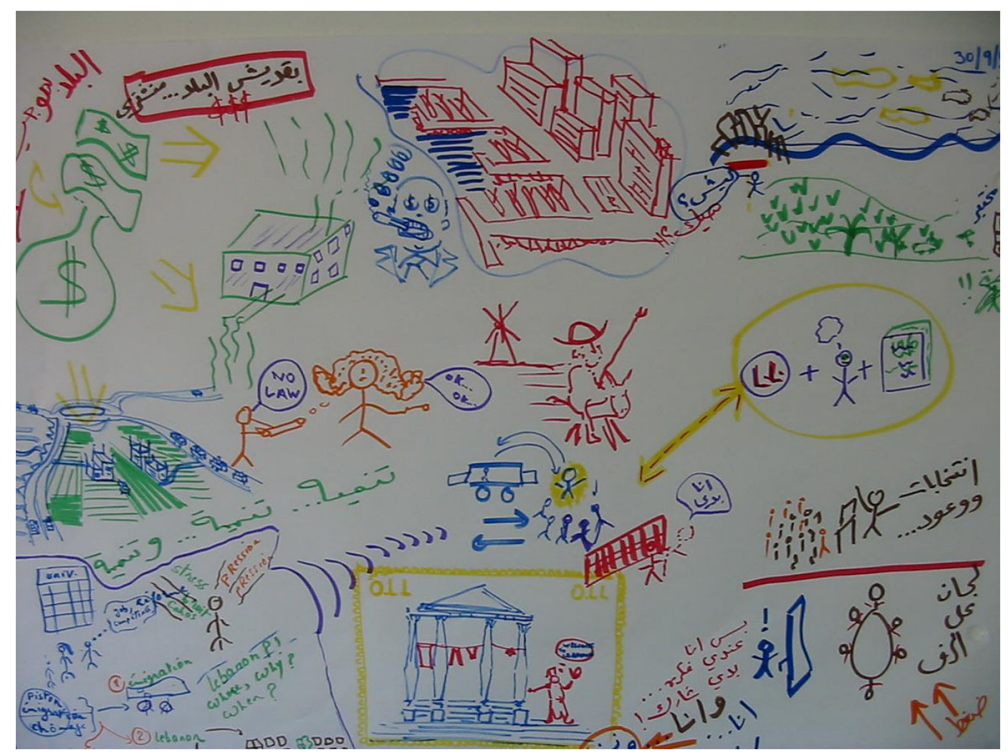

Fig. 3 A Rich Picture drawn in Lebanon 
Table 1. A content analysis of Fig. 3

\begin{tabular}{|c|c|c|}
\hline El themes & CA RP1 & Stakeholder EI RP1 \\
\hline Stakeholder style & $\begin{array}{l}23+\text { basic stick figures, } 2 \text { full } \\
\text { figures(B2,B3) }\end{array}$ & \multirow{14}{*}{$\begin{array}{l}\text { We are fighting against time ('chasing windmills' } \\
\text { like Don Quixote) - empty dreams. } \\
\text { _There is no development in the fields of } \\
\text { agriculture and fishery - no technological } \\
\text { advances. } \\
\text { _Elections are about empty promises and local } \\
\text { committees are papers on shelves [Dis]. } \\
\text { _Many have dreams and hopes but the door is } \\
\text { often closed unless they use 'wasta', i.e. personal } \\
\text { connections with powerful persons or groups [Dis]. } \\
\text { _Brain drain and emigration without return due to } \\
\text { high unemployment rates [Em]. }\end{array}$} \\
\hline $\begin{array}{l}\text { Facial expression/ } \\
\text { body language }\end{array}$ & $\begin{array}{l}\text { One clear face (B1) depicting a } \\
\text { person of power ( cigar and } \\
\text { dress). Body language of man } \\
\text { on Horse ( B2)looking } \\
\text { behind/being reflective }\end{array}$ & \\
\hline $\begin{array}{l}\text { Dominant } \\
\text { stakeholders }\end{array}$ & 6 instances: $B 2, B 1 \times 2, B 3, A 2, C 2$ & \\
\hline $\begin{array}{l}\text { Stakeholder } \\
\text { interaction } \\
\text { (groups, } \\
\text { communication) }\end{array}$ & $\begin{array}{l}2 \text { large Groups. One depicting } \\
\text { meeting (B3). }\end{array}$ & \\
\hline Background Space & $\begin{array}{l}\text { Majority of space used up in } \\
\text { picturing process }\end{array}$ & \\
\hline Dominant icons & $\begin{array}{l}\text { B1 ( large buildings), B2 ( } \\
\text { man/horse),B1 (interaction } \\
\text { with the law),B3 (items being } \\
\text { hung out to dry) }\end{array}$ & \\
\hline $\begin{array}{l}\text { Interesting } \\
\text { metaphor }\end{array}$ & $\begin{array}{l}\text { Man unable to access meeting } \\
\text { room (C3),items hung out to } \\
\text { dry (B3), legal issues (A2) }\end{array}$ & \\
\hline Isolation & $\begin{array}{l}\text { C2 ( visuals in yellow circle } \\
\text { border not recognisable) }\end{array}$ & \\
\hline Speech & All areas except B2 & \\
\hline $\begin{array}{l}\text { Orientation/readi } \\
\text { ng style }\end{array}$ & $\begin{array}{l}\text { No rotation required. Separate } \\
\text { story lines across many areas. }\end{array}$ & \\
\hline $\begin{array}{l}\text { Specific Icons: } \\
\text { Weather }\end{array}$ & $N \backslash A$ & \\
\hline $\begin{array}{l}\text { Specific Icons: } \\
\text { smoking } \\
\text { cigarette/cigar }\end{array}$ & 1 instance (B2) & \\
\hline $\begin{array}{l}\text { Specific Icons: } \\
\text { money }\end{array}$ & 1 instance of $\$(\mathrm{~A} 1)$ & \\
\hline $\begin{array}{l}\text { Specific Icons: } \\
\text { psychopathic }\end{array}$ & $N \backslash A$ & \\
\hline $\begin{array}{l}\text { Stakeholder } \\
\text { plenary reflections }\end{array}$ & \multicolumn{2}{|c|}{$\begin{array}{l}\text { This picture is an archive, the "story of the project to date" with the possibility of } \\
\text { coming up with new ideas throughout the CAMP process. There is less emphasis on } \\
\text { environmental challenges but what is positive is the focus on local participation and } \\
\text { the importance of teamwork. What is also unique is that there is a piece of every } \\
\text { person in that group in the picture. }\end{array}$} \\
\hline $\begin{array}{l}\text { Unique Signatory } \\
\text { of the RP }\end{array}$ & \multicolumn{2}{|c|}{$\begin{array}{l}\text { The RP depicts a colourful yet disorderly visual story of complex situations. There } \\
\text { seems to be numerous, possibly unrelated, communication issues which dominant } \\
\text { stakeholders are controlling. Problems drawn in visuals appear less negative than } \\
\text { those listed in the El. The stakeholder El does provide very strong confirmation of } \\
\text { the need for change alongside vast evidence of inadequate current practices. Sense } \\
\text { of disconnection is apparent alongside emigration issues and potential poor } \\
\text { governance. The plenary reflection presents a positive outlook for the future placing } \\
\text { emphasis on communication, teamwork and the importance of listening to the } \\
\text { whole community. }\end{array}$} \\
\hline
\end{tabular}

Key (not relevant to remaining tables - see separate key)

Yellow: [Dis] Sense of disconnection in decision making/ lack of power

Blue: [Em] Emigration

Pink: [Reg] Regulation/poor Government/Enforcement

Drawn from work, unpublished as yet by Berg, T. Bell, S. and Morse, S. Towards an Understanding of Rich Picture Interpretation for, by and with Community in Operations Research. 2017 
It is suggested that from the combination of interpretations of the original RP as contained in the EICA it is possible to educe the main themes of concern to the group who draw the RP. The EICA, when provided back to the participants in the workshop, can provide the basis for progress. In the case of $\mathrm{M}^{3}$ it was planned that a supplementary, second workshop should follow. At this workshop the original participants would be:

- Apprised of their original work

- Shown the EICA based signature for the first workshop as a whole

- Provided with a musical equivalent of the EICA based signature - this was an innovation on the method and was intended to provide a further creative catalyst to the participants

- Encouraged to design a technology which help to address the issues of concern noted in the first workshop.

\section{Co-Designing Considering Socio-Technical Requirements}

In line with the Socially-Aware Computing approach by Baranauskas (2014), this project understands technology design beyond defining technical requirements only.

Instead, design is considered a process originated in the society, embracing and surpassing informal aspects (e.g. peoples' values, beliefs, habits, etc.), and some formal ones (regulation, metrics, for instance), towards the construction of a technical system. The technical system, on the other hand, impacts the formal and informal levels, towards influencing people in the society. Creating a new technology demands the articulation of meanings in the social group also in the formal and informal aspects. Figure 4, adapted from Baranauskas (2014), illustrates that.

The Socially Aware Approach considers the involvement of social group with a diversity of experiences and worldviews in participatory design practices, including community leaders and other members, researchers, people with different familiarity with technology, etc., resulting in a more systematic view in the way technology is conceived and will shape our relationship with the world. The translation of the second workshop participants' ideas into technical, formal and informal requirements was inspired by this approach, as described in the next sections.

\section{The Application of Imagine to the Project Plan for $\mathbf{M}^{3}$}

Imagine makes use of Rich Pictures and EICA as a primary means for data gathering. It was applied in brief (three hour) collaborative workshops run by the team in May and July of 2016.

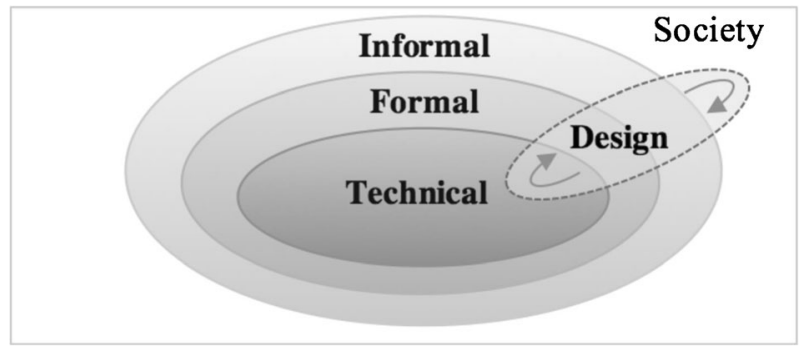

Fig. 4 The Socially-Aware Design Approach (From: Baranauskas 2014) 
Research Process - Workshop 1, 19th May

The First Workshop took place on the 19th May in Bletchley, Milton Keynes. 20 participants came to the event and developed their ideas in response to the question:

\section{"What do I Wish I'd Known before I set Out or during My Journey"}

Participants were asked to work in three groups of around 6 members and produce Rich Pictures in response to the question (Fig. 5).

The three groups produced a RP each and these were assessed.

\section{Analysis of Results of Workshop 1}

The RP produced by each of the three groups was assessed by means of the Content Analysis approach already described. The images were divided up into nine segments and each segment was assessed for content - strong images, visual metaphors, unique ideas, innovative concepts, repeated issues, tasks that needed to be addressed, etc. This assessment of the image was included with a review of the verbal report of each group which was provided at the event.

Figures 6, 7 and 8 are the segmented RPs assessed and Tables 2, 3 and 4 provide the resulting content analysis.

For each group we invited a composer to develop a musical interpretation of the RP. Our intention was to use this as a means to stimulate further creativity in the group at the second workshop.

The composer engaged to provide a musical interpretation of the RP from group 1 suggested the following assessment which can be seen as a companion piece to the Unique Signatory of the RP provided in the Content Analysis:

Group 1 RP is mainly about clear information, honest and integrated. The composer notes:

"I tried to incorporate many contrasting variables that all clearly work together in an organised fashion to reflect an 'integrated transport system'. There is a hint of sentimentality in the harmony which could imply an 'honest' system. The piece has a strong sense of direction musically which could reflect 'clear roads and a clear journey'".

(A segment of the musical notation for Group 1 is in Appendix 1).

Fig. 5 A picture from Workshop 1

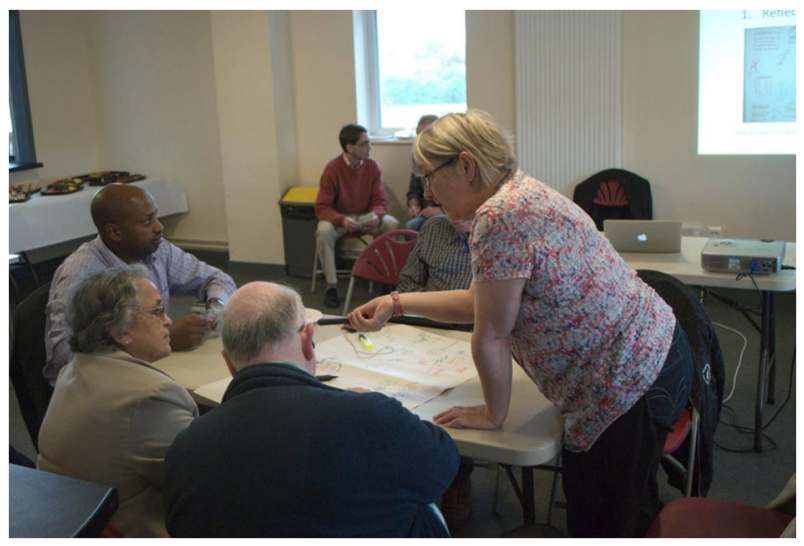




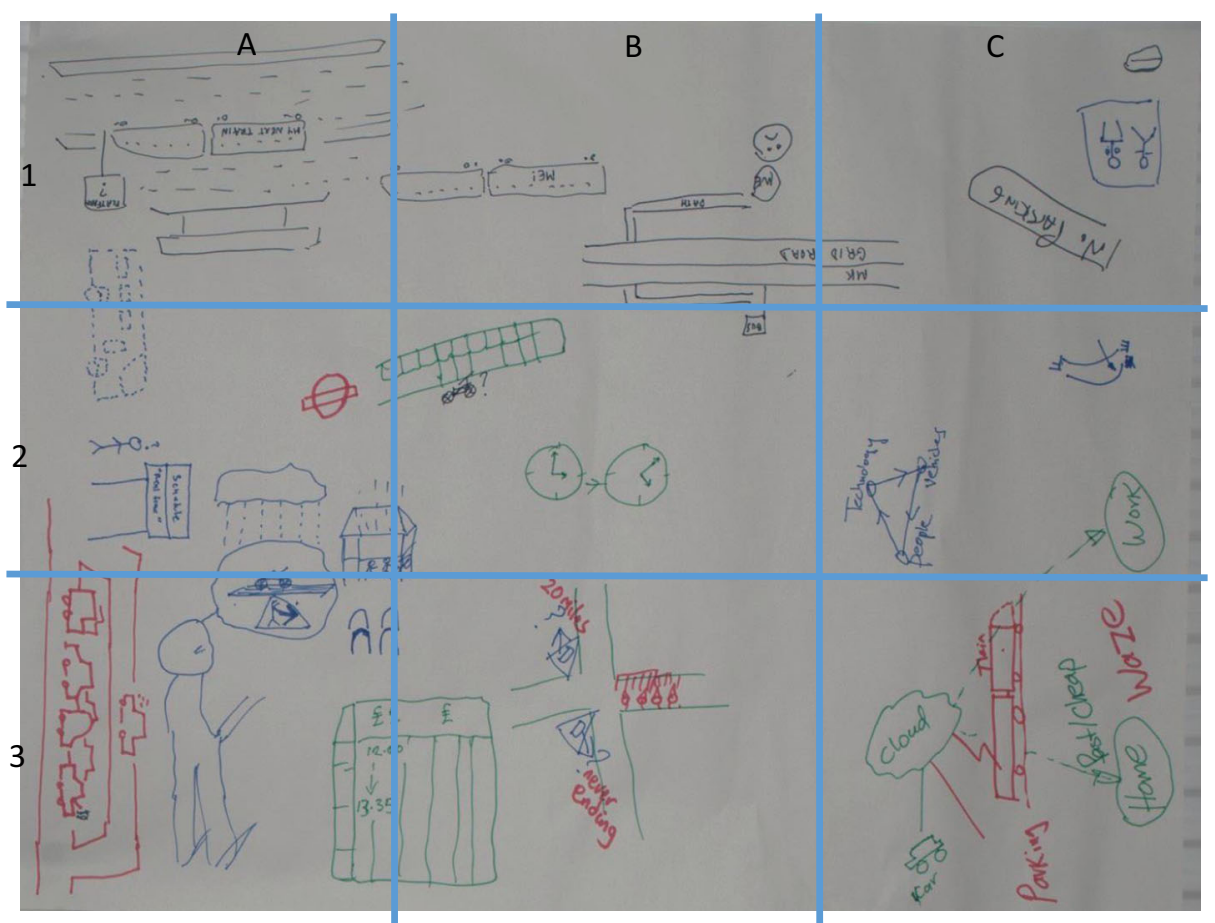

Fig. 6 Group 1 Rich Picture

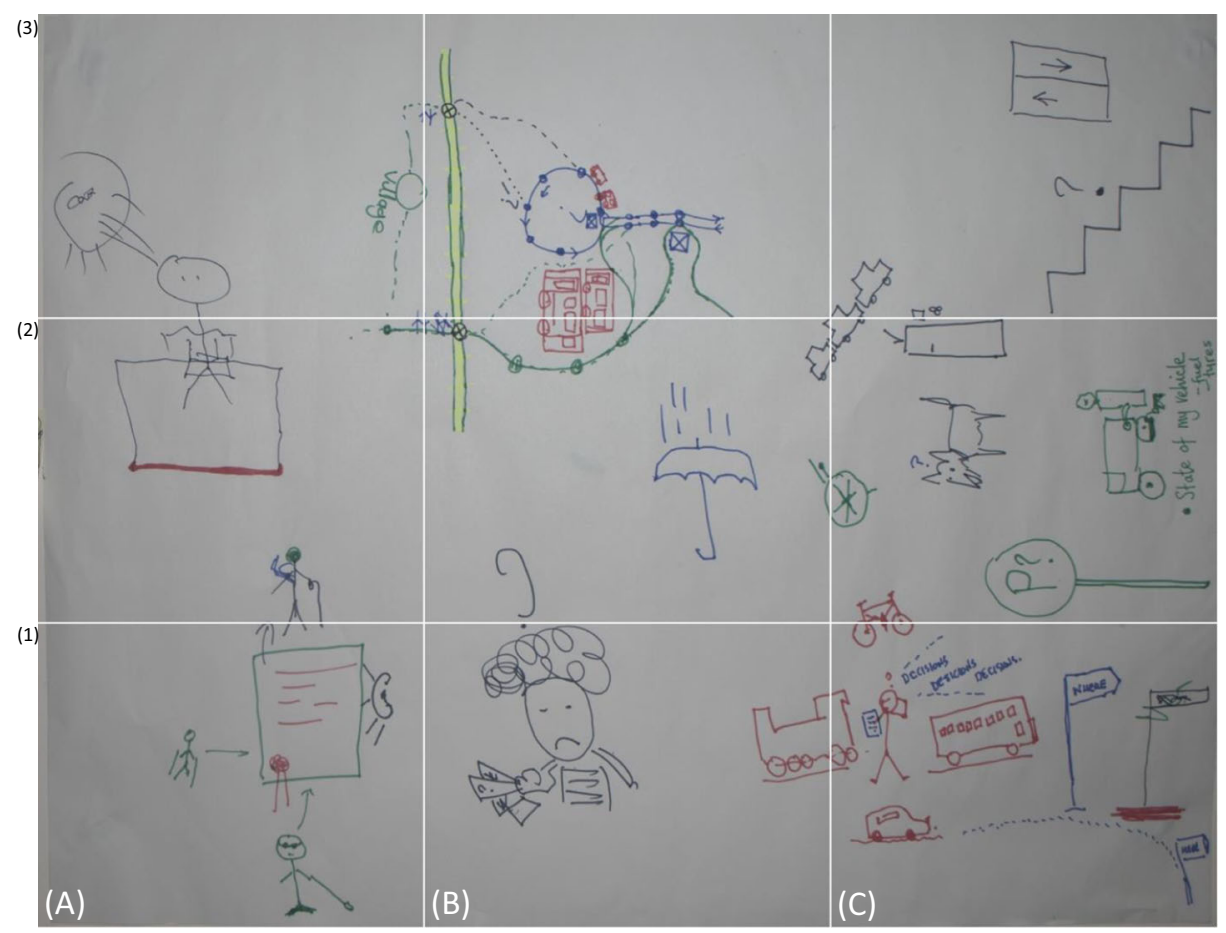

Fig. 7 Group 2 Rich Picture

\section{刑 Springer}




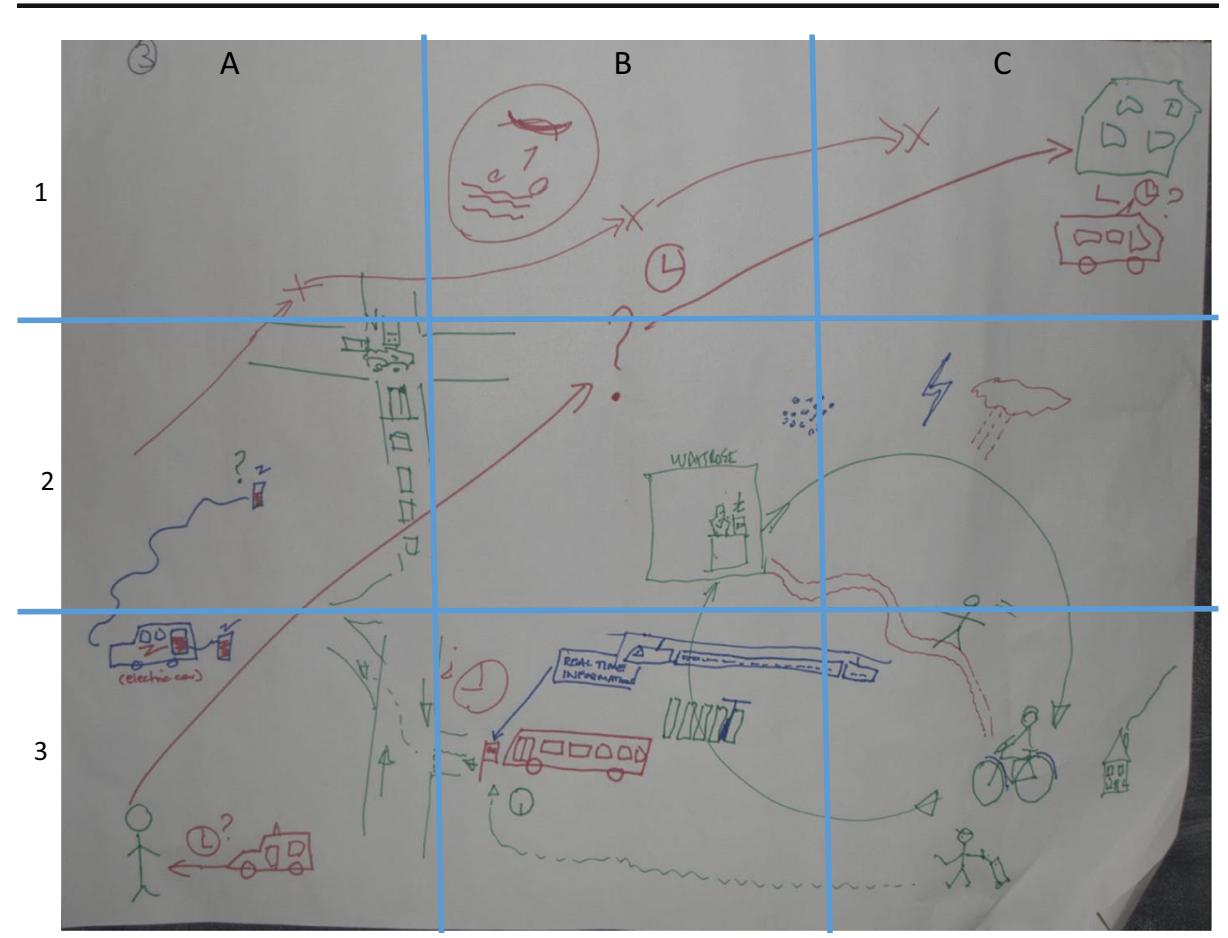

Fig. 8 Group 3 Rich Picture

It was observed that the groups listened with interest to the interpretation of each RP as a musical form while gazing the pictures. Group members noted a number of observations about the music. One suggested that it was 'interesting' and another noted that it was 'accurate'. Certainly the music provided a useful ice breaker to the main work of the Workshop process.

The musical assessment of the group $2 \mathrm{RP}$ was as follows:

Group 2 focuses on choices.

"The piece has a slower tempo to imply uncertainty. I have used rising melodies which are allowed to hang in mid-air as a 'questioning' device, and multiple resolutions to the same musical questions in different instruments. All instruments eventually arrive on the same chord at the end so the musical journey is completed safely but with a lot more uncertainty and decision making involved."

Group 3 the composer suggested were chiefly concerned with Time and Travel:

"This piece has the greatest sense of momentum to convey the sense that time and travel are of the essence. The woodwind part is deliberately busy to convey the 'congested world.' The piece regularly modulates to reflect the 'fractured world.' 'Not all choices are valid' so this piece demonstrates how the right choices will allow the traveller to successfully complete the journey".

\section{Emerging Themes from Workshop 1}

The EICA process provided three strong recurrent themes in the RPs. 
Table 2 Content Analysis of Group 1 Rich Picture

\begin{tabular}{|c|c|c|}
\hline El themes & CA RP1 & Stakeholder EI RP1 \\
\hline Parking & Where/How/Lack of C1 & \multirow{13}{*}{$\begin{array}{l}\text { Task 1: Integrate as in issue 2, and as is } \\
\text { already in place in London. } \\
\text { Task } 2 \text { - Create an oyster card for MK? } \\
\text { (Buses, Trains, Taxis, Parking). } \\
\text { Task } 3 \text { - Directions to available parking } \\
\text { spaces in real-time (y). } \\
\text { Issue 1: Information (b) can be inaccurate } \\
\text { and out of date(y). }\end{array}$} \\
\hline Trains & Where to change $\mathrm{A} 1$ & \\
\hline $\begin{array}{l}\text { Information(b) on } \\
\text { network }\end{array}$ & $\begin{array}{l}\text { Current state /Future. For } \\
\text { example, will bypass be busy in } \\
\text { one hour. Cost/Times (y). A3,C3 }\end{array}$ & \\
\hline Diversions & $\begin{array}{l}\text { Signs assume everyone is on } \\
\text { the diversion, may be going } \\
\text { elsewhere B3 }\end{array}$ & \\
\hline Inter-City Travel & $\begin{array}{l}\text { City-wide initiatives inadequate } \\
\text { A1 }\end{array}$ & \\
\hline $\begin{array}{l}\text { Interrupted } \\
\text { Journeys }\end{array}$ & $\begin{array}{l}\text { London has rich network - can } \\
\text { recover journey, Milton Keynes } \\
\text { network is thin and fragile - } \\
\text { difficult to recover A1 }\end{array}$ & \\
\hline Guarantees (gy) & $\begin{array}{l}\text { Limited accountability for } \\
\text { comfort, performance, } \\
\text { reliability. Multi-leg journeys in } \\
\text { particular (gy) A1 }\end{array}$ & \\
\hline False Information & Inaccurate bus info etc. A2, B1 & \\
\hline RedWays & $\begin{array}{l}\text { Poor surfaces (particular } \\
\text { problem for some health } \\
\text { issues), blocked routes A2 }\end{array}$ & \\
\hline Range Anxiety & $\begin{array}{l}\text { Petrol stations, EV charging, } \\
\text { Toilets C1 }\end{array}$ & \\
\hline Cycling & Weather A3 & \\
\hline Technology & $\begin{array}{l}\text { Interplay of people, systems, } \\
\text { vehicles. Integration c2 }\end{array}$ & \\
\hline Grid Roads & Congestion $\mathrm{A} 3$ & \\
\hline $\begin{array}{l}\text { Stakeholder } \\
\text { plenary reflections }\end{array}$ & \multicolumn{2}{|c|}{ Taking the mystery out of your journey } \\
\hline $\begin{array}{l}\text { Unique Signatory } \\
\text { of the RP }\end{array}$ & \multicolumn{2}{|c|}{$\begin{array}{l}\text { Desire to have "clear information, clear roads and a clear journey (b)" and an } \\
\text { "honest and integrated transport system (gn)". Toyed with variants about } \\
\text { "the journey is more important that the destination", joking about how that } \\
\text { may be fine metaphorically but it's not the best approach when one is } \\
\text { actually trying to get to places and get things done }\end{array}$} \\
\hline
\end{tabular}

Key (also relevant for the remaining Tables of Content Analysis) (Colours are coded to provide clarity in monochrome print)

Yellow (y) items around time - in all groups

Red (r) Choice and impacts on choice - in groups 2 and 3

Grey (gy) Predicaments related making decisions - in all group s

Light blue (b) items around information - in all groups

Green (gn) Honesty and practicality - in groups 1 and 2

Information:

All groups discussed the provision of information in some way, and tended to have strong feelings on it. Information came up as something which was unavailable (Group 1: G1), was 
Table 3 Content Analysis of Group 2 Rich Picture

\begin{tabular}{|c|c|c|}
\hline El themes & CA RP2 & Stakeholder EI RP2 \\
\hline $\begin{array}{l}\text { Central theme } 1 \text { - } \\
\text { choice and travel } \\
\text { (r) }\end{array}$ & $\begin{array}{l}\text { (C1) 'decisions decisions } \\
\text { decisions', which kind of } \\
\text { transport to use; how choice is } \\
\text { affected by price ( } r \text { ) (B1), } \\
\text { weather (B2), pets (C2), and } \\
\text { disability / health (C3) }\end{array}$ & $\begin{array}{l}\text { Task: Bring together movers from companies to } \\
\text { collaborate } \\
\text { Task: Inter-connecting services } \\
\text { Task: More electric buses }\end{array}$ \\
\hline $\begin{array}{l}\text { Central theme } 2 \text { - } \\
\text { bad information }\end{array}$ & $\begin{array}{l}\text { (C1) unclear signage; (A2/3) } \\
\text { unclear timetable; }(y) \text { idea of } \\
\text { too much information (b) } \\
\text { [spoken feedback] }\end{array}$ & $\begin{array}{l}\text { Issue: Journey guarantee: cost, delivery, time (y), } \\
\text { safety, comfort, }\end{array}$ \\
\hline Disjointedness & $\begin{array}{l}\text { (B3) complexity of routes and } \\
\text { lack of interconnections } \\
\text { between routes and providers }\end{array}$ & $\begin{array}{l}\text { Issue: Lack of coordinated thinking/planning for } \\
\text { future growth (infrastructure) }\end{array}$ \\
\hline Unpredictability & $\begin{array}{l}\text { (A1) desire for a charter that } \\
\text { guarantees the services } \\
\text { offered; (B1) unsure how much } \\
\text { service will cost }\end{array}$ & $\begin{array}{l}\text { Issue: Disjointed provision } \\
\text { Issue: Lack of political will }\end{array}$ \\
\hline Disruptions & $\begin{array}{l}\text { (C3) vertigo on escalators; (B2) } \\
\text { weather; (C2) dog; (B3) } \\
\text { disjointed route; (C2) state of } \\
\text { vehicle e.g. tyres, petrol }\end{array}$ & $\begin{array}{l}\text { Issue: Strategies produced for transport issues, but } \\
\text { no action plans / finance } \\
\text { Note: If you can make a timetable (y) for autistic } \\
\text { people you can make a timetable for everyone(y). }\end{array}$ \\
\hline $\begin{array}{l}\text { Stakeholder } \\
\text { plenary reflections }\end{array}$ & \multicolumn{2}{|c|}{ Aspirational ideas for a transportation and travel experience for the next generation. } \\
\hline $\begin{array}{l}\text { Unique Signatory } \\
\text { of the RP }\end{array}$ & \multicolumn{2}{|c|}{$\begin{array}{l}\text { For this group, choice(r) formed the basis of discussion. What can one choose to do } \\
\text { (r)? What choices are excluded from some users due to surrounding factors (ranging } \\
\text { from disability and health to the weather or bringing a pet). What happens when one } \\
\text { is not able to make a choice ( } r \text { ), for instance due to the information (b) one uses to } \\
\text { make the choice being of poor quality, or indeed there being too much data. Though } \\
\text { choice was a central part of the narrative ( } r \text { ) in this group's explanation, what they } \\
\text { seem more interested in is predictability. They want to know what's coming so they } \\
\text { can know if they can pay for(gy) it, access it, and use it comfortably and safely, and } \\
\text { they want to know that what's coming is certain, and that there is a come back if } \\
\text { what's expected is not delivered. }\end{array}$} \\
\hline
\end{tabular}

too poor (G2), provided in excess (G2), or unclear (G3). Groups wanted the right information rather than just more of it. This feeds into choice...

Choice:

Did not come up in G1 but did in G2 and G3. Choice was discussed as being limited by various factors, and also having choice was not always regarded in favourable terms ('decisions, decisions, decisions') (G2). Choice could be limited by external conditions like congestion, and the weather (discussed by all groups) (G3).

Groups oscillated between a preference for choice or information. Choice was not necessarily regarded as a useful good because it implies lack of information. When useful information is available, one does not have a choice as such, though this is a positive thing because the information tells you which option is the right option for you (i.e., it is quickest, most affordable, driest etc.).

Predictability:

Came up in all groups, and seemed to be the key theme. Groups discussed frustration and anxiety about things going wrong, and the ability of the MK transport network to recover from disruption (G1); the mystery in one's journey, and the extent to which there are any guarantees the MK transport services will actually provide what they say they are offering (G2 and G3). 
Table 4 Content Analysis of Group 3 Rich Picture

\begin{tabular}{|c|c|c|}
\hline El themes & CA RP3 & Stakeholder EI RP3 \\
\hline $\begin{array}{l}\text { Big question - } \\
\text { time and travel }(y)\end{array}$ & $\mathrm{B} 2 / 3, \mathrm{C} 2 / 3$ & \multirow{14}{*}{$\begin{array}{l}\text { Task: More non-fossil fuel propulsion } \\
\text { Task: Rome } 2 \text { Rio - multi modal data } \\
\text { Task: Promote human powered transport } \\
\text { Task: Link all fitness / leisure centres to } \\
\text { national grid } \\
\text { Issue: Increasing congestion } \\
\text { Issue: Poor infrastructure } \\
\text { Issue: Integrated RTPI for all modes of } \\
\text { transport } \\
\text { rked cars, cycle ways are few and walking is } \\
\text { ng alerted to realistic and to real-time choices } \\
\text { real impediments to getting to A and B. } \\
\text { ractured and congested world. Real } \\
\end{array}$} \\
\hline $\begin{array}{l}\text { Transport } \\
\text { metaphors }\end{array}$ & $\begin{array}{l}\text { C1 vehicle, } \mathrm{A} 2 \text { crossroads, } \mathrm{A} 3 \\
\text { electric car and van, } \mathrm{B} 3 \text { bus, } \mathrm{C} 3 \\
\text { bicycle }\end{array}$ & \\
\hline Local / National & $\begin{array}{l}\text { Long routes }-\mathrm{A} 3-\mathrm{B} 2-\mathrm{C} 1 \text { and } \\
\text { a cycle at } \mathrm{B} 3 / 3 \text { and } \mathrm{C} 2 / 3\end{array}$ & \\
\hline $\begin{array}{l}\text { Weather as a } \\
\text { factor }\end{array}$ & $\mathrm{C} 2$ thunder and rain. & \\
\hline $\begin{array}{l}\text { Real time/ virtual } \\
\text { (y) information (b) }\end{array}$ & B3 - buses and timetables (y) & \\
\hline Integrated travel & $\begin{array}{l}\text { B3 -A3 linked travel types by } \\
\text { information (b) }\end{array}$ & \\
\hline $\begin{array}{l}\text { Interesting } \\
\text { metaphor }\end{array}$ & $\begin{array}{l}\text { Pathways and people and bikes } \\
-B / C-2 / 3 \text {. }\end{array}$ & \\
\hline $\begin{array}{l}\text { Choices between } \\
\text { different options }\end{array}$ & $\begin{array}{l}\text { A3 and the route to Waitrose - } \\
\text { B2 }\end{array}$ & \\
\hline $\begin{array}{l}\text { Frustration and } \\
\text { anxiety about } \\
\text { travel }\end{array}$ & Frowny face B1 & \\
\hline Lack of choices & A2 - congested roads & \\
\hline $\begin{array}{l}\text { Travel specific } \\
\text { icons }\end{array}$ & $\mathrm{C} 1, \mathrm{~A} 2, \mathrm{~A} 3, \mathrm{~B} 3, \mathrm{C} 3 .$. & \\
\hline $\begin{array}{l}\text { Increasing } \\
\text { congestion }\end{array}$ & A2 - congested roads & \\
\hline $\begin{array}{l}\text { Stakeholder } \\
\text { plenary reflections }\end{array}$ & Time and Travel(y) & \\
\hline $\begin{array}{l}\text { Unique Signatory } \\
\text { of the RP }\end{array}$ & $\begin{array}{l}\text { Time, travel, choice (r) and no-choice. The group knows that the information } \\
\text { (b)system needs to operate in a fractured and congested world. Real } \\
\text { information needs to be linked to real impediments to getting to A and B. } \\
\text { Choice is (gn) vital but not all choices are valid (r). For example, cars are not } \\
\text { owned, buses cannot get past parked cars, cycle ways are few and walking is } \\
\text { infeasible for some journeys. Being alerted to realistic and to real-time choices } \\
\text { is vital.(gy) }\end{array}$ & \\
\hline
\end{tabular}

This was the key theme. People sought data which would allow them to make a transport decision whose outcome could be predicted.

From these three statements, and working in a similar manner to a Soft Systems development of a Root Definition (see for example the description in Checkland and Poulter 2006), the following "Theme statement" was produced:

\section{People Want Information which Provides Reliable Choice for Predictable Journeys}

This synthesis of the users' wishes, along with the interpretations of the RPs (including the musical interpretation), were to be the main inputs to the second workshop held in July. 


\section{Research Process Workshop 2 - 7th July}

On the 7th July ten members of the public attended the second workshop. Most of them, 9 out of 10, also participated in the first workshop (Fig. 9).

As Workshop 2 was related to technology design, it was important to build a panorama of the group's previous experience with technology and their age. Participants completed a form with this information and also stated their consent for having the data collected in the workshop published as a research study.

The age breakdown is shown in the pie chart in Fig. 10, and the relative technology usage made by the participants is shown in the histogram in Fig. 11.

Figures 10 and 11 provide us with an interesting observation. Generally speaking those who develop applications for the public are usually young, with a deep and often professional understanding of mobile technologies. In our sample the demographic is elderly and there is a diversity of understanding and experiences with technologies, including smartphones features usage, stated as a not frequent usage for 4 out of 10 participants, and different degrees of familiarity with other transport-related applications, such as SatNavs or Google Maps.

After experiencing the musical signature of the groups, some examples of data available and related technology were briefly presented as a way to inspire participants for the next activities. This presentation included screenshots of different types of GPSs, digital panels, bus-tracker and local weather forecast apps, accessibility resources for visually impaired in bus stops, etc.

Then, two tasks were proposed to the three groups of participants:

(I) "Describe yourselves using the new technology in your daily life"

A short scenario with a narrative illustrated the expected outcome for this task: "Before leaving home in the morning, Amy checks the BBC travel website. If the motorway (M1) is congested, she takes another secondary route".

The groups were invited then to share their scenario of technology usage with others.

The results suggested the context in which the technology would be applied by them. Planning a journey in advance, for instance in the beginning of the day, and associating that with other personal daily decisions and commitments were more important than supporting navigation in transit.

The three groups imagined a mobile app, two of them had a complementary website in the scenario.

Fig. 9 Picture from Workshop 2

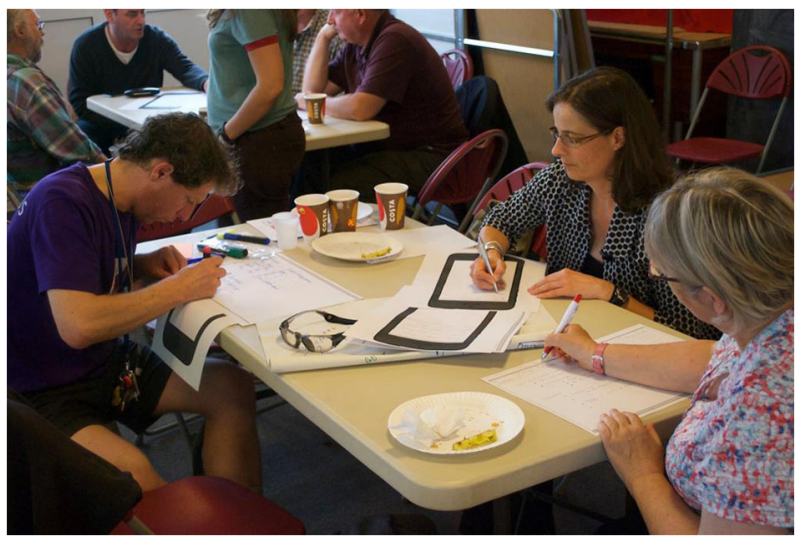


Fig. 10 Pie chart of age of those attending the second workshop

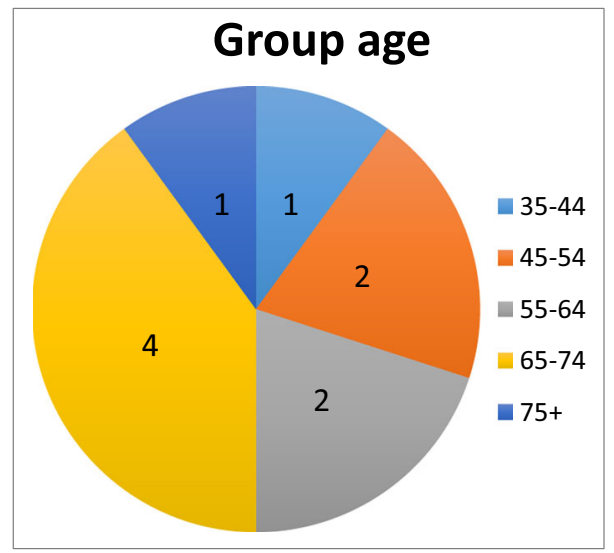

(II)

"What does your technology look like?"

The second task invited the groups to draft the user interface of their "desirable" technology meeting the challenge of the Theme statement that emerged from Workshop 1. They should evidence what sort of data they expected to see there.

Our literature review informed us that the ways data are employed by users depends on a number of factors, the trade off between their wider ambitions for urban space versus their immediate, personal transport needs; their broader familiarity with public transport networks; and the time at which they seek to access the data available which might be prior to departure or might be en route. In keeping with the openness embedded in the Imagine methodology, our intention was to avoid guiding participants in any way rather than encouraging them towards a specific type of application or data presentation tool. They produced a range of ideas about the potential applications. Some of the resulting ideas are illustrated in Fig. 12.

Overall, the three groups suggested a number of concerns, ideas, and wishes in their drafts that were later classified as informal, formal and technical aspects.

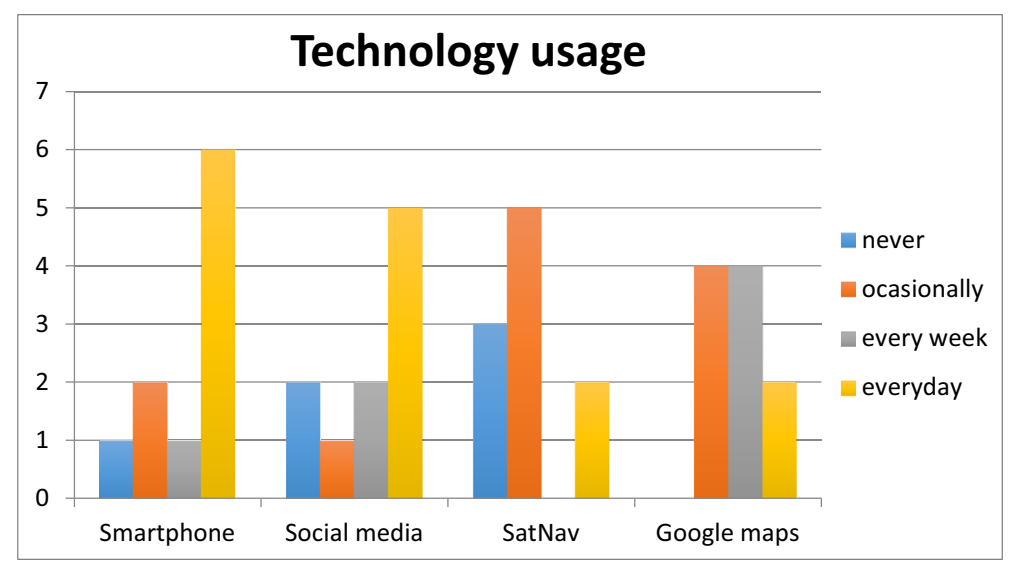

Fig. 11 Histogram of technology usage 


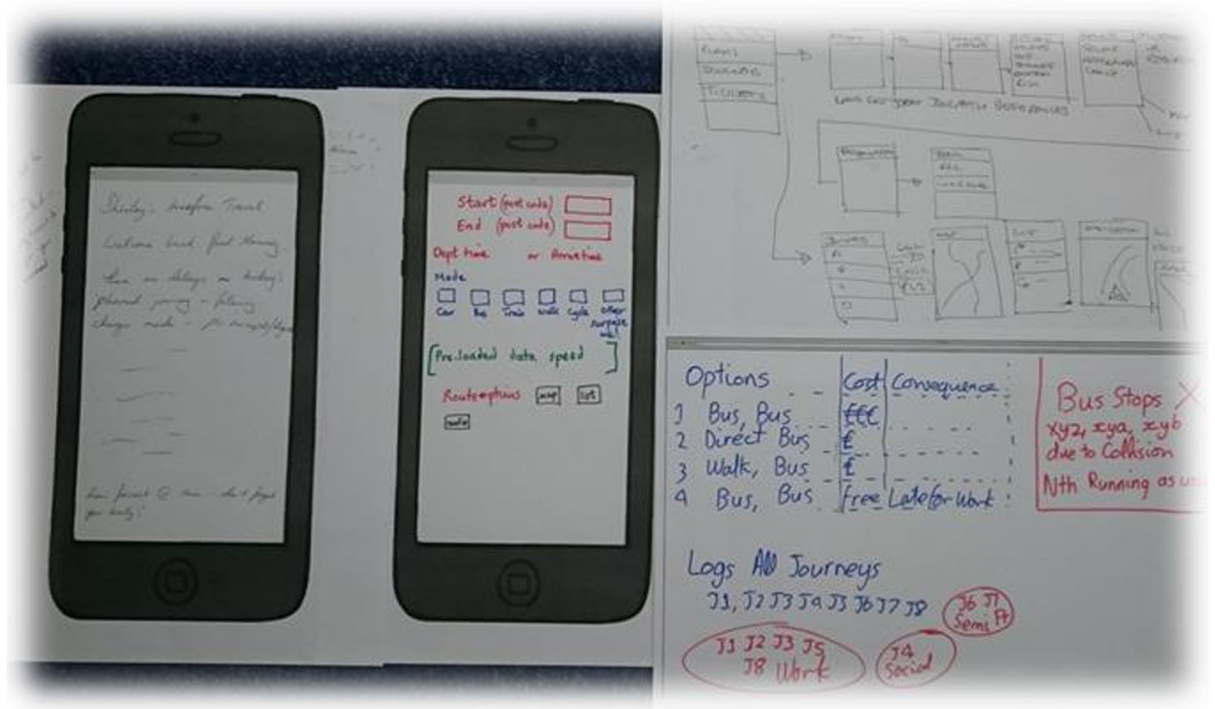

Fig. 12 Resulting co-design activities

The informal aspects raised mainly their perception on current transport-related technology evidencing how they would like to see technology supporting their daily lives, complementing and reinforcing the findings of the first workshop (Table 5).

The formal concerns discussed reflected the UK's transport system organisation, in which private systems work independently, on their own schedules and providing their own online services. Participants recognised this as a challenge when integrating information in a new technology. It is not only about presenting information from different sources together, but also reflecting the impact of one system to the others. For instance, connecting schedules of buses and trains. They also would like to see the system connected to external services that would add extra value, such as buying tickets with a discount or earning loyalty card points.

In technical terms, some participants would like to see the planning system integrated with their personal online calendar. Also, as previously mentioned, they made clear the interest for

Table 5 Informal aspects collected in the workshop 2

Current perception

Overwhelmed with too much information, when it is available (inappropriate data visualisations)

Lack of reliability of train and bus schedules in Milton Keynes

The motorways conditions are hard to predict
Expectations. The new technology should:

Support planning to avoid risks. Showing benefits and consequences of different options for a journey and alerting for unexpected events.

Personalised planning, connected to individuals' preferences and other commitments in daily routine (i.e. alerting for the eventual need of child care when going out).

Planning journeys in advance (not like a satnav that is used to check the route when the journey starts)

Making journey planning personal and contextual, considering individuals' pace, typical journeys, etc. Giving personal advice like to dress, need for umbrella, etc.

Evidence the impact of decisions considering personal values such as punctuality, being eco-friendly, saving money. 
having a new mobile app, although not all participants have smartphones or use mobile data, considered expensive. A web version to be used at home has been also cogitated, as well as an app using the minimal possible data.

Working from the suggestions contained in groups work, the conceptual designs set out in Figs. 13, 14 and 15 emerged.

\section{Discussion}

As has already been noted, much work in the area of transport provision in Smart Cities relates to quantitative data focused on expert interpretation of need. The version of the Imagine methodology applied in this case had a clearly participatory focus and provided a small group of stakeholders with the opportunity to engage thoughtfully with the complexities of transport provision. As one attendee at the second workshop noted:

"My company is going crazy trying to plan our transport policy. We thought that this workshop might help".

Methods to allow citizens to engage in complex planning and assessment processes exist in many domains but are rarely reported with regard to Smart City transport. Despite (or because of) the informal and systemic nature (including sweeping in complexity rather than trying to simplify) of the Imagine method and specifically Rich Picture format seemed to find resonance and even reflief with some of those attending.

The workshop participants expressed their preference for an app that would collect data from different sources, such as traffic reports, weather forecasts, transport timetables and ticket purchase platforms and combine it with user-provided data such as calendar information and journey preferences. One significant element that emerged from the co-design process was the

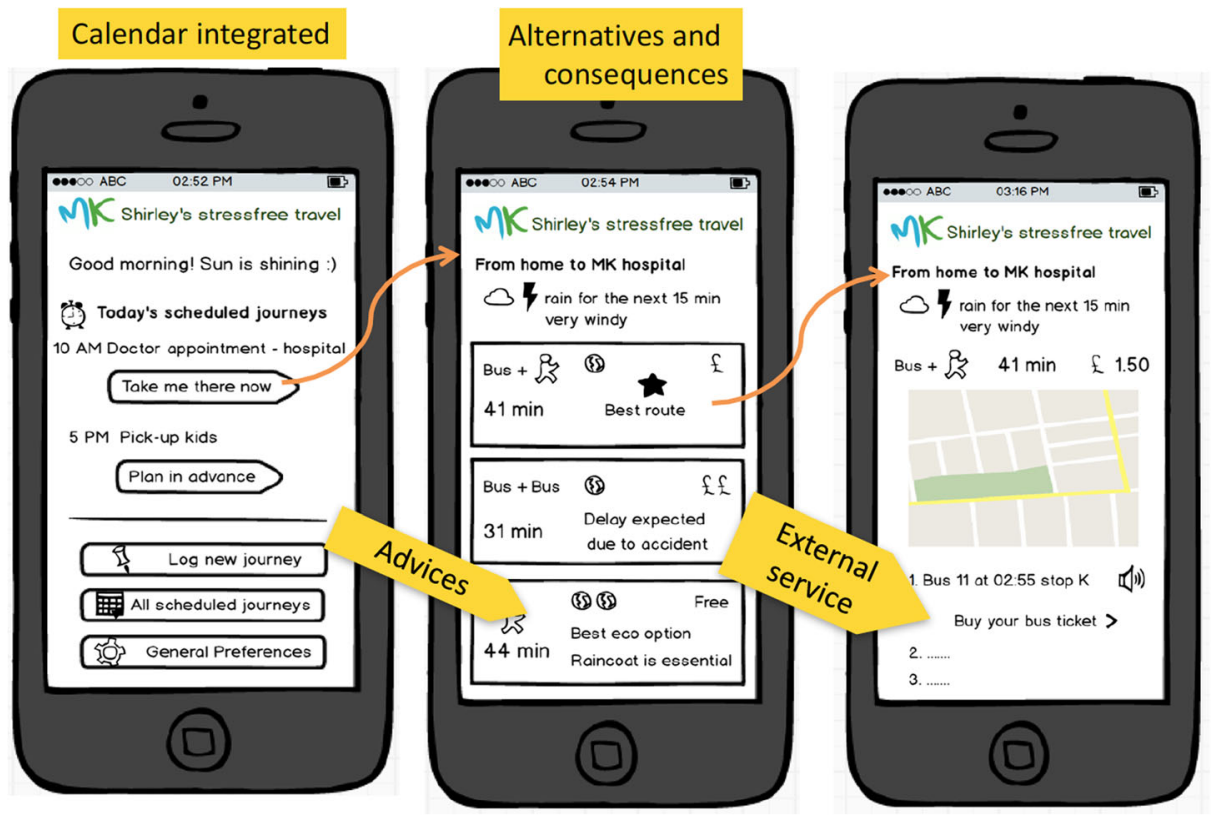

Fig. 13 Overview - 'Shirley's stress free travel' (name suggested by one of the groups) 


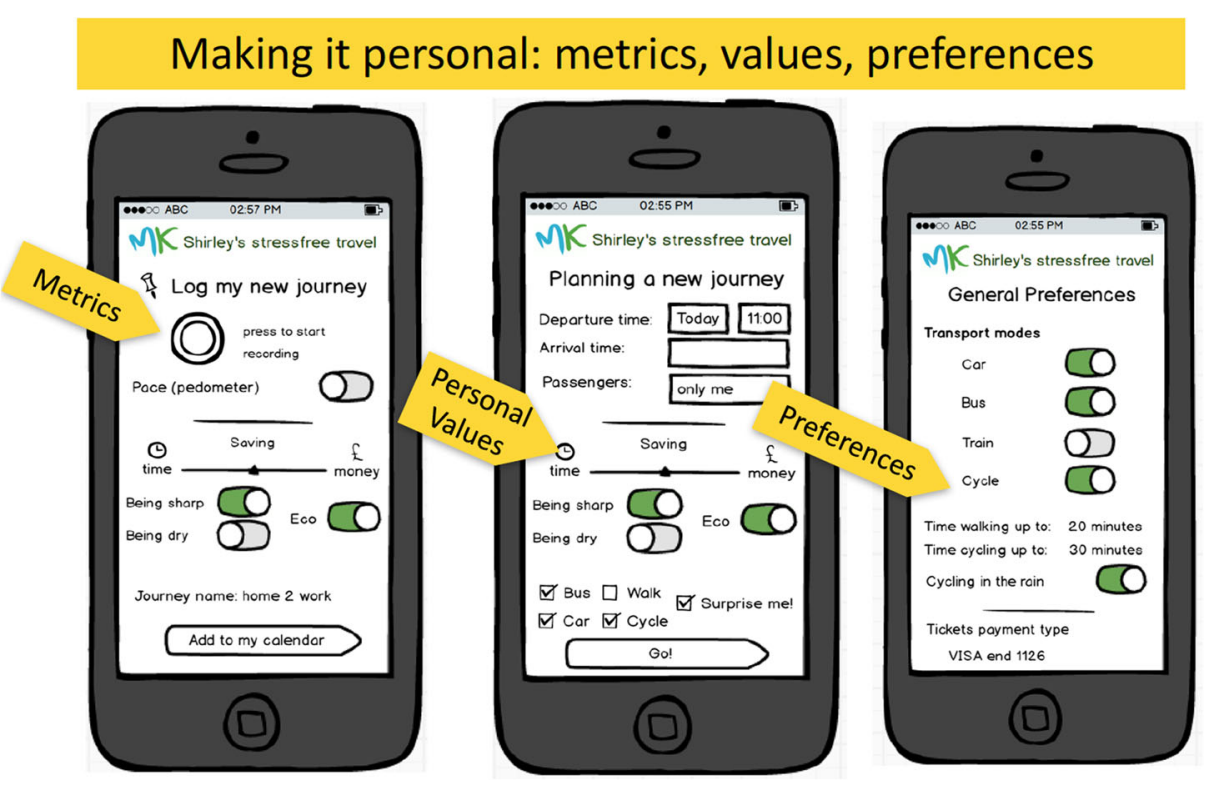

Fig. 14 Making it personal

users' preference for a narrative app interface that could articulate options and provide reminders in a semblance of dialogue with the users. It would be worth pursuing in further research whether this more dialogic tone ("would you like to change your departure time?") could help app users feel more empowered compared to a more mandatory tone ("change departure time now"). The Rich Pictures from the first workshop depicted users as the passive

\section{Predictability}
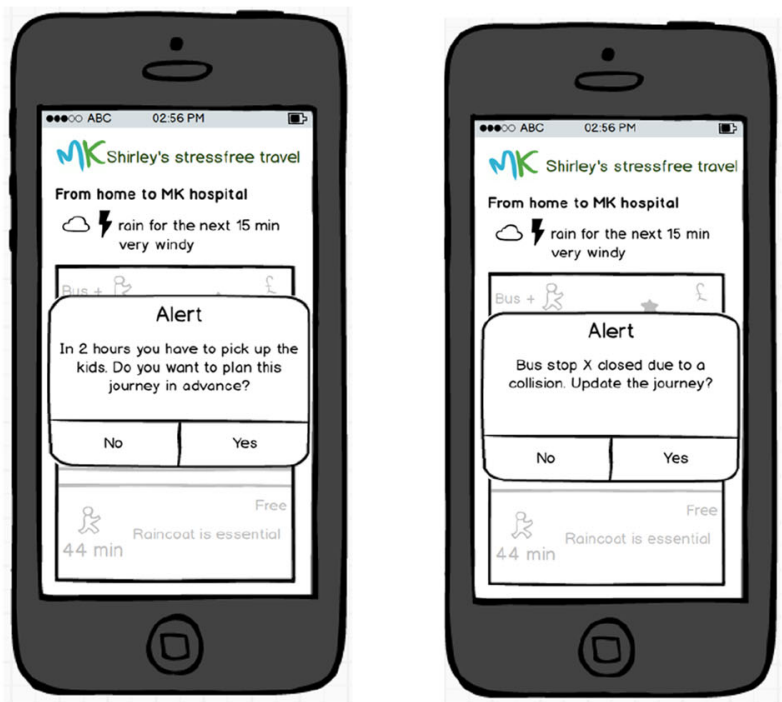

Fig. 15 Predictability 
victims of unknowable events outside their control. The app design process instead told a story casting users as the protagonists of their own travel narrative and making meaningful decisions with the help of data.

One notable aspect of the exercise was the importance attached to uncertainty of information in various forms. Risk, predictability and reliability were all key themes. Participants were keen to assess and reduce the risk of delays and inconvenience in their journeys, they were concerned about the predictability of journey times and the reliability of information from timetables. Those considering walking and cycling were concerned about weather, in which a finite degree of uncertainty is normally assumed inevitable, and often quantified to some degree in forecasts, whereas users of all kinds of motorised transport were concerned about the predictability of delays caused by traffic, accidents, and possibly in some cases lack of coherent transport provision and planning. The extent to which participants recognised the probabilistic nature of uncertainty in all of these sources was unclear and would in any case be variable across a larger user group. Nevertheless, the assumed purpose of transport information to facilitate better choices implies a necessary engagement with decision-making under uncertainty and an information application that failed to deal with this aspect by warning of risks and quantifying likely delays would probably share the same judgement of unreliability conferred on the timetable information available in the present data landscape, that generally ignores this aspect. Consideration and quantification of journey options in a probabilistic sense, perhaps through processing of a growing user-generated dataset, thus appears to be a valuable possibility for future information applications. Anecdotal evidence even points to the potential value of highly specific localised information, for instance regular bus users are sometimes aware of predictable delays to specific buses related to school opening times or regular heavy use by senior-citizen free pass users.

While gathering and analysing such data pose a set of interesting challenges, the presentation of uncertainty information to users provides yet another set of challenges, particularly when information overload has been explicitly cited as a problem. Numerous techniques exist for presenting uncertainty information to non-expert users, such as the use of blur and transparency, cf. the review of Bonneau et al. 2014, and the frequency-based diagrams exemplified in the review by Spiegelhalter et al. (2011). We leave this as an aspect for further research, noting that allowing for uncertainty in suggesting transport options could well lead on to complex decision problems that might also depend on a set of user preferences.

\section{Conclusions}

In this paper we have attempted to explain how the rapid and participatory $\mathrm{M}^{3}$ research project has provided innovation in systems method and interpretation of participant engagement. In the specific domain of smart cities research the project has addressed the participation gap identified in the literature by:

- Giving research participants a voice in the data collection landscape, and

- Allowing research participants without technical expertise to have a role in app design

This inclusion provided room for insight and a more holistic interpretation of transport provision and future planning. Further, by providing a musical interpretation of Rich Picture 
visualisation the project has provided a suggested avenue for further consideration in the encouragement of participant engagement in problem structuring.

Acknowledgements The authors are grateful to the Open University for providing the seed funding which allowed this research to proceed. We also thank Community Action: MK for their support and the workshops participants for their commitment and enthusiasm.

\section{Appendix 1. Segment of musical notation Group 1}

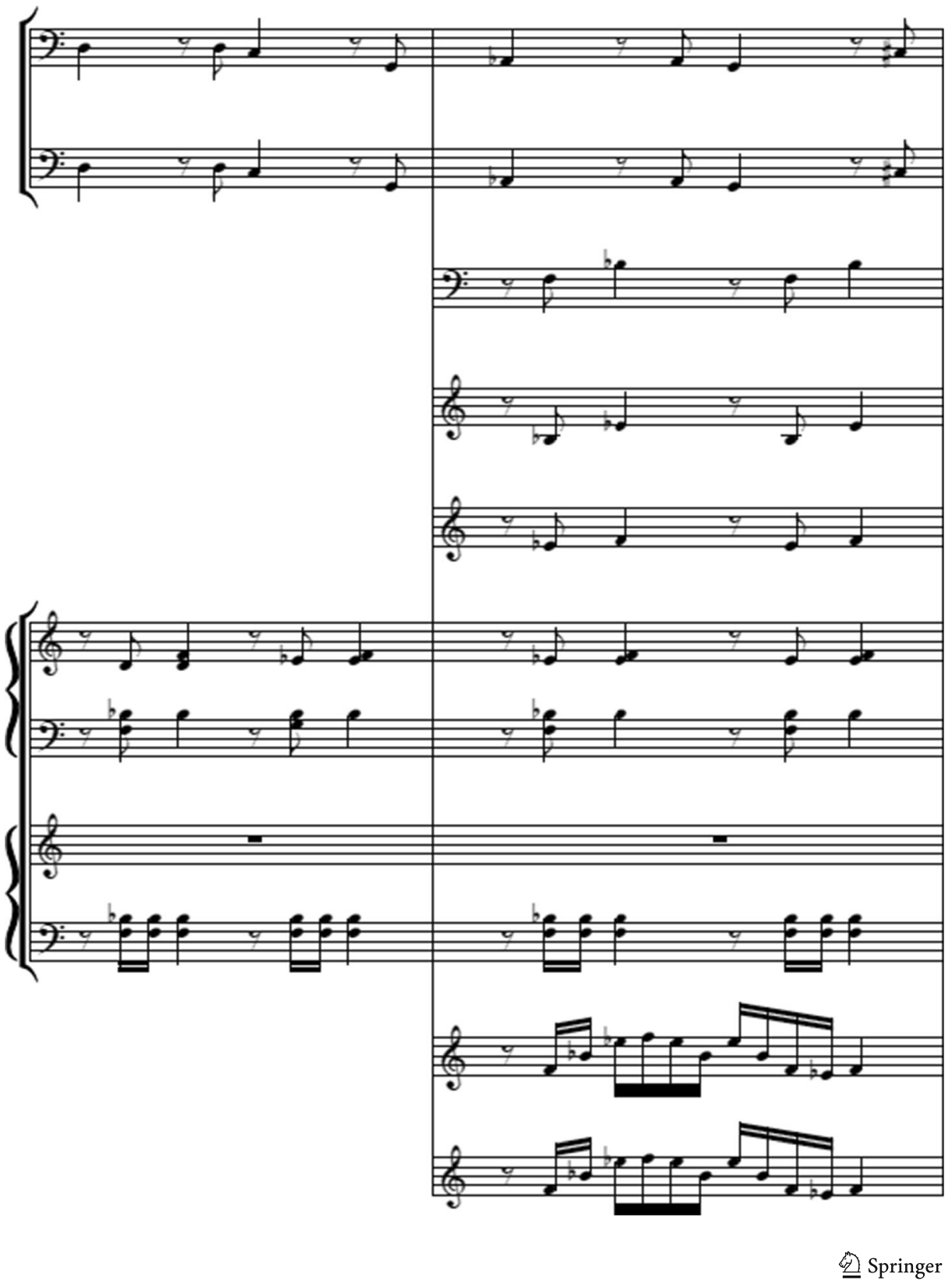


Open Access This article is distributed under the terms of the Creative Commons Attribution 4.0 International License (http://creativecommons.org/licenses/by/4.0/), which permits unrestricted use, distribution, and reproduction in any medium, provided you give appropriate credit to the original author(s) and the source, provide a link to the Creative Commons license, and indicate if changes were made.

\section{References}

Allwinkle S, Cruickshank P (2011) Creating smart-er cities: an overview. Journal of Urban Technology 18(2):1-16 Anon (2016) MK Hackathon - a hackathon for the good of Milton Keynes [Online]. Available at https://www. mkhackathon.org/. Accessed 2 May 2017.

Avoine $\mathrm{G}$ et al (2014) Passengers information in public transport and privacy: can anonymous tickets prevent tracking? Int J Inf Manag 34(5):682-688

Bagchi M, White PR (2005) The potential of public transport smart card data. Transp Policy 12(5):464-474

Baranauskas MCC (2014) Social awareness in HCI. Interactions. ACM, 21(4):66-69. DOI:10.1145/2621933

Baraniuk C (2013) The civic hackers reshaping your government. New Sci 218(2923):36-39

Barbeau SJ, Borning A, Watkins K (2014) OneBusAway multi-region-rapidly expanding mobile transit apps to new cities. J Public Transp 17(4):3

Bell S, Berg T, Morse S (2015) Rich pictures: sustainable development and stakeholders - the benefits of content analysis. Sustainable development. Available at: http://doi.wiley.com/10.1002/sd.1614

Bell S, Berg T, Morse S (2016) Rich Pictures: encouraging resilient communities. Routledge, London

Bell S, Correa Peña A, Prem M (2013). Imagine coastal sustainability. Ocean Coast Manag 83:39-51. Available at: http://inkinghub.Elsevier.Com/retrieve/pii/S0964569113000483. Accessed 12 Nov 2014

Bell S, Morse S (2010) Triple task method: systemic, reflective action research. Syst Pract Action Res 23(6):443452 Available at: http://oro.open.ac.uk/24612/

Bell S, Morse S (2013) Groups and facilitators within problem structuring processes. J Oper Res Soc 64:959-972

Bonneau G-P, Hege H-C, Johnson CR, Oliveira MM, Potter K, Rheingans P, Schultz T (2014) Overview and state-of-the-art of uncertainty visualization. In Hansen CD, Chen M, Johnson CR, Kaufman AE, Hagen H (eds) Scientific visualization: uncertainty, multifield, biomedical, and scalable visualization. Springer, London, p 3-27

Buscher M, Shapiro D, Hartswood M, Proctor R, Slack R, Voss A, Mogensen P (2002) Promises, premises and risks: sharing responsibilities, working up trust and sustaining commitment in participatory design projects. pp 183-192. Available at: http://libezproxy.open.ac.uk/login?url=http://xml.engineeringvillage2. org/controller/servlet/Controller?CID=expertSearchDetailedFormat\&EISESSION=1_94257f1299b32f43 dM276ses3\&SYSTEM_USE_SESSION_PARAM=true \&SEARCHID=da9ea412980a07fac7c5dprod4 data $1 \&$ DOCINDEX $=4 \&$ PAGEINDEX $=1 \&$ RESULTSCOUNT $=194 \&$ database $=3 \&$ format $=$ expertSearchDetailedFormat

Carlsson-Kanyama A et al (2008) Participative Backcasting: a tool for involving stakeholders in local sustainability planning. Futures 40:34-46

Chambers R, Paradigm Shifts and the Practice of Participatory Research and Development (1995) In: Nelson N, Wright S (eds) Power and participatory development. Intermediate Technology Publications, London

Checkland P, Poulter J (2006) Learning for action: a short definitive account of Soft systems methodology, and its use, practitioners, teachers and students. John Wiley and Sons Ltd., Chichester

Cinderby S (2010) How to reach the "hard-to-reach": the development of Participatory Geographic Information Systems (P-GIS) for inclusive urban design in UK cities., Area, 42, p. 20100601 239-251. Available at: http://libezproxy.open.ac.uk/login?url=http://search.ebscohost.com/login.aspx?direct=true\&AuthType= ip, url,cookie, uid\&an $=50211042 \& \mathrm{db}=$ s3h\&scope $=$ site $\&$ site $=$ ehost

Coskun V et al (2014) Development and performance analysis of Multifunctional City smart card systems. Int J Comput Inform Syst Control Eng 8(2):297-300

Desouza KC, Bhagwatwar A (2012) Citizen apps to solve complex urban problems. J Urban Technol 19(3):107-136

Farag S, Lyons G (2010) Explaining public transport information use when a car is available: attitude theory empirically investigated. Transportation 37(6):897-913

Farag S, Lyons G (2012) To use or not to use? An empirical study of pre-trip public transport information for business and leisure trips and comparison with car travel. Transp Policy 20:82-92

Farkas K et al (2014) Participatory sensing based real-time public transport information service. In pervasive computing and communications workshops (PERCOM workshops), 2014 I.E. international conference on. IEEE, pp 141-144

Farkas K et al (2015) Crowdsending based public transport information service in smart cities. IEEE Commun Mag 53(8):158-165 
Fraser EDG et al (2006) Bottom up and top down: analysis of participatory processes for sustainability indicator identification as a pathway to community empowerment and sustainable environmental management 78 , pp. 114-127. Available at: http://libezproxy.open.ac.uk/login?url=http://search.ebscohost.com/login. aspx?direct=true \&AuthType=ip,url,cookie, uid\&an=19322651\&db=a9h\&scope=site \&site=ehost

Gabrys J (2014) Programming environments: environmentality and citizen sensing in the smart city. Environ Plan D Soc Space 32(1):30-48

Gammer N, Cherrett T, Gutteridge C (2014) Disseminating real-time bus arrival information via QRcode tagged bus stops: a case study of user take-up and reaction in Southampton, UK. J Transp Geogr 34:254-261

Grotenhuis J-W, Wiegmans BW, Rietveld P (2007) The desired quality of integrated multimodal travel information in public transport: customer needs for time and effort savings. Transp Policy 14(1):27-38

Jotin Khisty C, Zeitler U (2001) Is hypermobility a challenge for transport ethics and Systemicity? Syst Pract Action Res 14(4):597-614

Kitchin R (2014) The real-time city? Big data and smart urbanism. GeoJournal 79(1):1-14

Kolb D (1984) Experiential learning: experience as the source of learning and development. Prentice-Hall, London

Lisson C, Hall M (2016) Do we choose what we desire?-persuading citizens to make consistent and sustainable mobility decisions. University of Nebraska, Omaha. USA. Part of the mental and social health Commons, other computer sciences Commons, sociology of culture Commons, transportation Commons, and the urban studies Commons

Mac-Gillavry E (2013) Collaborative mapping and GIS: an alternative geogrpaphic information framework. Webmapper, Amsterdam

Mirri S et al (2014) On combining crowdsourcing, sensing and open data for an accessible Smart City. In IEEE, pp:294-299

Mitchell V et al (2015) Empirical investigation of the impact of using co-design methods when generating proposals for sustainable travel solutions. CoDesign. doi:10.1080/15710882.2015.1091894

Nishiuchi H, King J, Todoroki T (2013) Spatial-temporal daily frequent trip pattern of public transport passengers using smart card data. Int J Intell Transp Syst Res 11(1):1-10

Nuzzolo A et al (2013) An advanced pre-trip planner with personalized information on transit networks with ATIS. In: 16th international IEEE conference on intelligent transportation systems (ITSC 2013). IEEE, pp 2146-2151

Paradi-Guilford C et al (2013) Cairo transport app challenge: leveraging ICT entrepreneurship and open innovation to solve daily challenges, The World Bank

Pelletier M-P, Trépanier M, Morency C (2011) Smart card data use in public transit: a literature review. Transp Res C Emerg Technol 19(4):557-568

Pidd M (2011) From problem-structuring to implementation. J Oper Res Soc 39(2):115-121

Salim FD (2012) Probing streets and the built environment with ambient and community sensing. J Urban Techno 19(2):47-67

Sanders EB-N, Stappers PJ (2008) Co-creation and the new landscapes of design. CoDesign 4(1):5-18

Spiegelhalter D, Pearson M, Short I (2011) Visualizing uncertainty about the future. Science 333:1393-1400. doi:10.1126/science. 1191181

Thiagarajan A et al (2010) Cooperative transit tracking using smart-phones. In proceedings of the 8th ACM conference on embedded networked sensor systems. ACM, pp 85-98

Tomitsch M, Haeusler MH (2015) Infostructures: towards a complementary approach for solving urban challenges through digital technologies. J Urban Technol 22(3):37-53

Trozzi $\mathrm{V}$ et al (2015) Effects of countdown displays in public transport route choice under severe overcrowding. Netw Spat Econ 15(3):823-842

Ülengin F et al (2010) A problem-structuring model for analyzing transportation-environment relationships. Eur J Oper Res 200(3):844-859 Available at: http://www.sciencedirect.com/science/article/pii/S0377221709000368

Velaga NR et al (2012) Transport poverty meets the digital divide: accessibility and connectivity in rural communities. J Transp Geogr 21:102-112

Zegras PC et al (2015) Tracing a path to knowledge? Indicative user impacts of introducing a public transport map in Dhaka, Bangladesh. Camb J Reg Econ Soc 8(1):113-129 